\title{
SUSPENSÃO DE CIRURGIAS: ATITUDES E REPRESENTAÇÕES DOS ENFERMEIROS
}

\section{SURGERY SUSPENSION: NURSING ATTITUDES AND SOCIAL REPRESENTATION*}

\author{
Maria Jésia Vieira** \\ Antonia Regina F Furegato***
}

VIEIRA, MJ; FUREGATO, ARF Suspensão de cirurgias: atitudes e representações dos enfermeiros. Rev Esc Enf USP, v. 35, n. 2, p. 135-40, jun. 2001.

\section{RESUMO}

O presente trabalho faz considerações sobre a representação social dos enfermeiros acerca da suspensão de cirurgias e suas atitudes diante do problema. Os dados foram coletados através de entrevistas com roteiro temático e posterior categorização das atitudes verbalizadas. Para a análise do conteúdo utilizou-se o referencial teórico das "Representações Sociais". Os resultados foram sistematizados obedecendo a uma Escala de Atitudes que variou desde a Passividade, com persistência de traços culturais de submissão, ligados a uma forma tradicional de exercício, até Ações ativas, autônomas, de enfrentamento, destinadas a resolver o problema da suspensão de cirurgias e/ ou minimizar suas conseqüências.

PALAVRAS-CHAVE: Psicologia social. Comportamento. Enfermagem de centro cirúrgico.

\begin{abstract}
'
The present work make considerations about the nurses social representation of surgery suspension and their attitudes in front of the problem. The dates was collected through interviews whit thematic guide and later categorization of attitudes in front of the problem. By the analysis of the contents verbalized by nurses it was used the theoretical background of the Social Representations. The results was systematized in a Attitude Scale that varied from Passivity with persistence of cultural traces of submission, like a traditional form of working, to Active Actions, with autonomy, destined to resolve the problem of surgery suspension or reduced its consequences.
\end{abstract}

KEYWORDS: Psychology social. Behavior. Operating room nursing.

\section{INTRODUÇÃO}

A ocorrência de suspensão de cirurgias, configurada como o adiamento em atender à necessidade de recuperação do paciente, tem repercussões as mais diversas, podendo chegar até à rejeição psicológica deste procedimento terapêutico pelo paciente, conforme demonstrado em trabalho anterior de VIEIRA (1982) bem como nos de BIANCHI (1983), YAKOTA (1983), CAVALCANTE; PAGLIUCA; ALMEIDA (2000).
O paciente, geralmente sob "stress" pelo enfrentamento de uma situação desconhecida mas necessária, depara-se com a informação de que a sua cirurgia não será mais realizada na data e hora previstas. Esta suspensão é caracterizada pelo adiamento da intervenção cirúrgica após ter-se iniciado seu preparo pré-operatório imediato. Dentre as razões para esta ocorrência, os autores citados

Trabalho apresentado no $51^{\circ}$ Congresso Brasileiro de Enfermagem, realizado em Florianópolis, de 02 a 07 de outubro de 1999 , classificado em $2^{\circ}$ lugar no Prêmio Wanda de Aguiar Horta.

** Enfermeira, Doutora, Professora Adjunta no Depto de Enfermagem do Centro de Ciêncías Biológicas e da Saúde da Universidade Federal de Sergipe. Endereço: rua Ministro Domício Fraga, n 111, ed. IBIZA, apto 404, Jardins. 49025-000 Aracaju - Sergipe. Fone (079) 2312280. E-mail: mjvieira@infonet.com.br

*** Enfermeira, Doutora, Professora Titular no Depto de Enfermagem Psiquiátrica e Ciências Humanas da Escola de Enfermagem de Ribeirão Preto - USP. E-mail: furegato@glete.eerp.usp.br 
referem e discutem as ausências e atrasos da equipe cirúrgica, falhas de comunicação entre equipe médica, centro cirúrgico e unidades de internação, falta de material ou insumos necessários à cirurgia, falhas no preparo pré-operatório, assim como falta de exames de laboratório, entre outras.

Nestes estudos, as reações manifestadas pelos pacientes foram de tristeza, desânimo, agressividade, revolta ou choro. Alegam terem se sentido inferiorizados, inseguros, desconfiados da equipe cirúrgica. Alguns tendem a rejeitar a cirurgia com medo de que este incidente seja um "aviso" (de forças sobrenaturais) para não serem operados.

Algumas causas do problema podem ser evitáveis, dependendo de planejamento e entro-samento entre Centro Cirúrgico e Unidade de Internação, assim como de estabelecimento de sistemáticas que atendam à programação cirúrgica, sem adiamentos desnecessários, conforme os autores referidos.

O desejo, manifestado por diretores de hospitais e enfermeiros entrevistados, de encontrar formas de diminuir a incidência e minimizar as conseqüências, foi evidenciado desde o primeiro estudo citado. Temse, ao longo do tempo, observado que a questão vem suscitando discussões e, nos hospitais estudados em por VIEIRA (1982), tem sido evidente a redução da incidência de suspensões.

Entretanto, incidentes desta natureza ainda acontecem e, mesmo com menor freqüência, são igualmente prejudiciais aos pacientes.

Outros estudos, discutem a fragilidade do poder que compromete a ação do enfermeiro, especialmente no Centro Cirúrgico, onde se cria uma dicotomia entre a atribuição de inúmeras responsabilidades e tarefas sem a garantia da necessária autonomia na tomada de decisões (VIEIRA 1986; AVELAR, 1995; AVELAR; JOUCLAS, 1992; BIANCHI; JOUCLAS, 1994).

Entendendo, entretanto, que esta conquista é necessária ao exercício da Enfermagem e reafirmando a importância de minimizar a ocorrência da suspensão de cirurgias, visando diminuir as conseqüências que acarretam para o paciente, nos propusemos a verificar, como estão se configurando, no presente momento, as atitudes dos enfermeiros diante do problema "suspensão de cirurgias", à luz do referencial teórico das "Representações Sociais".

O termo "Representações Sociais", conforme SA (1993), designa "tanto um conjunto de fenômenos quanto o conceito que os engloba e a teoria constituída para explicá-los" (p.19), identificando um vasto campo de estudos psicossociológicos onde, tanto o social como o individual têm legitimidade, a partir dos conceitos formais apresentados por MOSCOVICI em "La psicanálise, son image et son public" (1976).

Este autor sistematizou a teoria das Representações Sociais, fazendo uma ponte entre a sociologia e a psicologia, através de "uma modalidade específica de conhecimento que tem por função a elaboração de comportamentos e a comunicação entre indivíduos". Nela têm lugar a "plasticidade, a mobilidade e a circulação das representações contemporâneas emergentes, descobrindo a estrutura e os mecanismos internos destas representações". Elas devem ser consideradas como teorias do senso comum, ciências coletivas pelas quais se procede a interpretação e a construção das realidades sociais.

As Representações Sociais apresentam uma estrutura de dupla natureza - conceptual e figurativa vez que é uma instância intermediária entre a percepção e o conceito, sendo estes intercambiáveis e se engendrando reciprocamente. Assim, surgem as noções de figura e significado, entendendo-se que toda figura tem um sentido e de todo sentido emerge uma figura, conforme colocado pelo próprio MOSCOVICI (1976).

Conforme SOUZA FILHO (1993), as representações sociais resgatam o papel do sujeito como produtor de sistemas simbólicos e sociais, a ênfase no estudo de sistemas simbólicos complexos, as interações intra e intergrupos, assim como o funcionamento e mudanças da sociedade.

Com base nestas considerações, o presente trabalho tem como objetivos:

a)identificar as atitudes dos enfermeiros diante do problema "suspensão de cirurgias";

b)discutir estas atitudes à luz do referencial teórico das Representações Sociais.

\section{O MÉTODO UTILIZADO}

SPINK (1993) e SOUZA FILHO (1993) referem que as Representações Sociais convivem com diferentes vertentes de pesquisa e niveis de realidade, permitindo a aplicação de variadas óticas e recortes tais como a ênfase no produto ou processo, a elaboração das representações ou sua relação com o comportamento. Assim sendo, torna possivel o uso de vários procedimentos para a coleta e a análise dos dados, preservandose sempre o rigor metodológico correspondente.

No presente trabalho, usou-se a entrevista com tema fazendo às enfermeiras, componentes da amostra a seguinte solicitação: "Por favor, fale sobre como se sente em relação ao problema 'suspensão de cirurgias"'. $\mathrm{O}$ foco de atenção desta pesquisa diz respeito às referências das mesmas sobre suas atitudes diante da ocorrência do problema.

A análise dos dados foi feita segundo a técnica da análise categorial temática descrita por BARDIN (1977) e adaptada para este estudo. Consistiu em classificar os diversos elementos da comunicação, a partir de leituras que permitiram identificar o sentido, colocando em ordem as idéias expressas pelos entrevistados. Esta categorização é um procedimento 
sistemático que permite descobrir os "núcleos de sentido" expressos nas falas dos entrevistados e que contém significados relativos às atitudes dos enfermeiros frente à suspensão de cirurgias.

\section{APRESENTAÇÃO E ANALISE DOS DADOS}

Considerando-se que a pesquisa de atitudes hoje, tinha como referência aquelas expressas pelos enfermeiros na pesquisa de VIEIRA (1982), foi usada quantitativamente a mesma amostra, nos mesmos hospitais, ou sejam: 1 hospital de grande porte e três de médio, entrevistando-se em cada um deles 01 enfermeiro de centro cirúrgico, correspondendo à lotação total daquele momento, e 02 enfermeiros de unidades de internação cirúrgica, na cidade de Aracaju, estado de Sergipe. Realizaram-se, portanto, 12 entrevistas com 4 enfermeiros de Centro Cirúrgico e 8 de Unidades de Internação.

Dos núcleos de sentido extraídos do conteúdo expresso, emergiram 4 temas, apresentados no QUADRO I, acompanhados dos comportamentos referidos pelos enfermeiros diante do problema.

QUADRO I - Temas emergentes da configuração de atitudes a partir das representações dos enfermeiros sobre seus comportamentos frente à suspensão de cirurgias e respectivos núcleos de sentido.

\begin{tabular}{|c|c|c|}
\hline Atitudes configuradas & Comportamentos referidos & Núcleos de sentido \\
\hline Passividade & $\begin{array}{l}\text { - tem pena do paciente e não sabe o que fazer pois, na maioria das } \\
\text { vezes, o problema não depende da enfermagem. } \\
\text { - sente dificuldade de avisar o paciente quando a cirurgia é } \\
\text { suspensa. } \\
\text { - sente-se impotente em relação às conseqüências para paciente }\end{array}$ & $\begin{array}{l}\text { - não sabe o que fazer } \\
\text { - sente dificuldade } \\
\text { - sente-se impotente }\end{array}$ \\
\hline Inquietação & $\begin{array}{l}\text { - revolta-se com os problemas, principalmente quando os mesmos } \\
\text { podem ser evitados. } \\
\text { - questiona a passividade dos enfermeiros } \\
\text { - irrita-se por não ser dada a devida consideração ao paciente }\end{array}$ & $\begin{array}{l}\text { - revolta-se } \\
\text {-questiona os outros } \\
\text { - irrita-se }\end{array}$ \\
\hline Envolvimento & $\begin{array}{l}\text { - procura saber os motivos } \\
\text { - inquieta-se com o problema porque se sente responsável pelo } \\
\text { paciente }\end{array}$ & $\begin{array}{l}\text { - procura saber os motivos } \\
\text { - sente-se responsável }\end{array}$ \\
\hline $\begin{array}{l}\text { Ações resolutivas } \\
\text { Enfrentamento }\end{array}$ & $\begin{array}{l}\text { - certifica-se das causas e encaminha os problemas para soluções } \\
\text { administrativas ou técnicas quando cabíveis } \\
\text { - orienta o pessoal de enfermagem no sentido de não contribuir } \\
\text { com } \\
\text { o problema } \\
\text { - orienta o pessoal de enfermagem sobre os prejuízos que o } \\
\text { problema causa ao paciente } \\
\text { - conversa com os pacientes explicando os motivos e tentando } \\
\text { diminuir suas tensões } \\
\text { - encoraja o paciente para a nova marcação de cirurgia tentando } \\
\text { fazê-lo confiar na cura } \\
\text { - orienta o paciente sobre os cuidados a tomar até a nova } \\
\text { marcação da cirurgia }\end{array}$ & $\begin{array}{l}\text { - certifica-se das causas } \\
\text { - encaminha } \\
\text { - orienta } \\
\text { - orienta } \\
\text { - conversa } \\
\text { - explica os motivos } \\
\text { - tenta diminuir tensões } \\
\text { - encoraja } \\
\text { - orienta }\end{array}$ \\
\hline
\end{tabular}

Foi interessante notar que as atitudes referidas, mesmo com falas e freqüência diferentes, corresponderam aos mesmos núcleos de sentido daquelas verificadas em 1982, por VIEIRA, nos mesmos hospitais.
Embora cada núcleo de sentido possa estar presente em mais de uma entrevista, e, da mesma forma, cada entrevista tenha incluído um ou mais núcleos de sentido, observou-se que uma das entrevistas apresentou exclusivamente atitudes de passividade, uma apenas de inquietação e uma de passividade e 
inquietação, formando um conjunto de 3 entrevistas apresentando atitudes de não envolvimento, para um total de 12.

Não se pretende questionar se esta falta de envolvimento estaria ligada a atributos de ordem pessoal ou a questões de gênero, com conotações de aceitação e submissão, ou se estaria ligada a traços profissionais, de caráter antropológico e históricocultural.

A intenção é discutir a representação da suspensão da cirurgia que neste caso foi considerada como uma ocorrência indesejável para o paciente. Entende-se que esta representação foi ancorada nos conceitos de que a cirurgia é um procedimento necessário ao tratamento do mesmo e de que o enfermeiro é um profissional cuja função tem sido focalizada no cuidar, englobando as ações de "proteger, fortalecer, aliviar", citadas por PASSOS (1996). Como decorrência, uma vez marcada a cirurgia, entendem os enfermeiros que são necessários todos os esforços e condições para que a mesma se realize.

Estes conceitos têm sido veiculados ao longo dos tempos, na formação do enfermeiro, fazendo parte do seu dia a dia e, consequentemente da sua cultura profissional.

Dentro desta perspectiva, a suspensão da cirurgia foi interpretada cognitivamente como ocorrência que vai de encontro aos objetivos da assistência à saúde, orientando condutas, sejam de valoração negativa, sejam de envolvimento ativo para resolver o problema, conforme discussão de JODELET (1984), sobre os processos de ancoragem e objetivação das representações.

Autores como FRASER (1994), FARR (1985), BOCK, FURTADO e TEIXEIRA (1988), e LAPLANTINE (1989) estabelecem íntima relação entre atitudes e representações sociais, relacionandoas com o conhecimento, o afeto, o valor $\mathrm{e}$ as experiências. Entretanto, a Representação Social é mais abrangente por englobar principios geradores da tomada de posições, orientar a própria ação a partir das predisposições desenvolvidas pela internalização dos valores, tendo este processo um caráter dinâmico.

Objetivou-se esta representação através do discurso que expressa suas atitudes frente à mesma, caracterizando-se pela passividade, passando pela inquietação, pelo envolvimento, chegando até as ações resolutivas, e de enfrentamento.

Estas atitudes decorrem, por sua vez, de contingências que ancoram a prática profissional, podendo influenciar diferentemente o comportamento dos profissionais.

A PASSIVIDADE, embora em princípio não seja esperada no contexto da prática profissional, pela postura ideológica de defesa do paciente, reflete, dificuldades nas relações profissionais. A pressão exercida sobre as pessoas, seja pelas relações de poder profissional, ou seja pelo poder institucional, dificulta a tomada de posições pelo enfermeiro, por não ser ele elemento hegemônico dentro do contexto das instituições de saúde, conforme discutido por VIEIRA (1986), CARAPINHEIRO (1993) AVELAR (1995), entre outros.

No contexto do Centro Cirúrgico, como nas demais áreas do hospital, configura-se a imagem da enfermeira, ao mesmo tempo, como aquela que lidera uma equipe, reproduzindo a relação dominaçãosubordinação, e aquela subjugada pelos poderes instituídos culturalmente nos serviços de saúde quais sejam o poder médico e o poder administrativo (CARAPINHEIRO, 1993).

Assim, estas enfermeiras descrevem atitudes de "ter pena", "sentirem-se impotentes", "não saberem o que fazer" e "sentirem dificuldade de avisar o paciente".

A atitude de INQUIETAÇÃO provocada pela suspensão de cirurgias pode, com freqüência, gerar comportamentos de revolta. Duas das entrevistas revelaram apenas esta atitude; em outras quatro, ela foi acompanhada de envolvimento ou ação, traduzindo, no primeiro caso, ainda uma situação próxima à passividade, vez que só há um envolvimento psicológico afetivo com a situação, mas não necessariamente um comportamento ativo procurando explorar e buscar soluções para a mesma. Neste tema, foram identificados os núcleos de sentido: revolta, questionamento da passividade dos enfermeiros e irritação pela desconsideração com o paciente.

O terceiro tema que inclui as atitudes de ENVOLVIMENTQ traduz um nivel comportamental com predisposição para a ação. Expressa componentes cognitivos quando "procura saber os motivos" e componentes afetivos quando "inquieta-se com o problema porque se sente responsável pelo paciente". Estes componentes das atitudes, expressos pelo afeto, pela cognição e pelo comportamento foram descritos por LIMA (1994) que também refere, entre outras formas de análise de atitudes, aquela feita por escalas contendo as dimensões avaliativa (bom-mau, agradável-desagradável), de potência (grande-pequeno, forte-fraco) e de atividade (ativo-passivo, rápidolento).

O quarto tema, que revela atitudes com maior grau de atividade foi composto por AÇÕES resolutivas e de enfrentamento do problema. Entre estas ações, encontram-se: 1) as que se dirigem diretamente à solução do problema, de acordo com as causas, seja pela via administrativa ou técnica; 2) as que visam orientar a equipe de enfermagem sobre os prejuizos para o paciente, no sentido de que esta não contribua para a incidência do problema; 3) as que visam dar o cuidado direto ao paciente, conversando, explicando as causas, tentando diminuir suas tensões psicológicas, encorajando-os a confiar na cura, preparando-os para uma nova marcação da cirurgia ou 
orientando-os sobre os cuidados necessários até esta nova marcação, quando a causa foi falta de condições fisicas do mesmo ou necessidade de maior preparo.

Estas representações, expressas por atitudes, constituíram o que MOSCOVICI (1978) refere como "um corpus organizado de conhecimentos" expresso em atividades psíquicas graças às quais os homens podem compreender a realidade fisica e social, podem inserirse num grupo ou numa ligação quotidiana de trocas e liberar os poderes de sua imaginação".

Os núcleos de sentido referentes aos temasatitudes que emergiram das entrevistas constituem, segundo a Teoria das Representações Sociais, o processo de objetivação pelo qual os indivíduos e os grupos conseguem dar à figura um sentido, dar materialidade a um abstrato, naturalizá-la. Entretanto, o núcleo figurativo, em função de alguns traços histórico-culturais da profissão, não se mostrou suficientemente estruturado para determinar condutas coerentes com a dimensão avaliativa destas representações, vez que alguns entrevistados ainda referem atitudes de passividade.

No que diz respeito a esta dimensão avaliativa, ou função de interpretação da realidade, todos os participantes deste estudo consideraram a suspensão de cirurgias uma experiência ruim e desagradável para o paciente, enquanto que as dimensões de potência e atividade variaram de acordo com o disposto no Quadro I.

Tem-se, entretanto que pensar as representações sociais sempre como um processo dinâmico, pois, como refere SPINK (1993), o enfoque das representações sociais requer um triplo esforço, ou seja, "compreender o impacto que as correntes de pensamento veiculadas em determinadas sociedades têm na elaboração das representações sociais"; "entender o papel das representações na orientação dos comportamentos e na comunicação", com sua força enquanto sistema cognitivo de acolhimento de novas informações; e "entender seu papel nas mudanças e transformações sociais"(p.89).

É possivel verificar a persistência de atitudes marcadas pela força do poder hegemônico sobre a Enfermagem, incluindo passividade e submissão, ligadas a configurações históricas mais remotas dentro do modelo médico tradicional. Por outro lado, percebem-se representações que conferem à Enfermagem a responsabilidade pela defesa do paciente, o poder de enfrentamento com interferência ativa na situação, um campo de atribuição e ação próprias, o que se aproxima de um contexto cultural a que GUIMELLI; JACOBI (1990) chamam de uma prática nova, com autonomia e saber específicos. Esta prática compõe-se de ações resolutivas, dirigidas às necessidades da pessoa, em cada contexto. (ver figura em anexo).

As atitudes são, portanto, coerentes com estas representações, orientando comportamentos, de acordo com as mudanças sócio profissionais, mudanças estas que vão sendo absorvidas pelos diversos elementos da equipe, no ritmo e no tempo necessários à integração do novo, no cotidiano de cada um. Percebe-se, nesta situação, pelas manifestações dos enfermeiros, maior índice de envolvimento, o que pode significar a absorção crescente desta prática nova.

\section{CONSIDERAÇÕES FINAIS}

Embora tenha sido observada, neste estudo, a persistência de atitudes de passividade do enfermeiro, em relação à suspensão de cirurgias, foi possível verificar, com maior expressividade, atitudes ativas para resolver ou minimizar o problema, coerentes com as representações de poder esperadas atualmente deste profissional, responsável pelo cuidado ao paciente e pelas equipes de Enfermagem.

O referencial teórico das Representações Sociais possibilitou a percepção e a análise destas atitudes, considerando-as como ancoradas nas concepções que os profissionais têm do seu papel e, de igual forma, a tradução destas concepções em ações objetivadas.

Coerente com este referencial, o estudo aponta para o entendimento de um contexto de mudanças, onde se pode observar tanto a persistência de traços culturais ligados a uma forma tradicional de exercício, caracterizada pela submissão e passividade, quanto a adoção de atitudes de enfrentamento, tomada de posições ativas, configurando a autonomia decorrente de um papel próprio no exercício do cuidado ao paciente.

\section{REFERÊNCIAS BIBLIOGRÁFICAS}

AVELAR, MCQ. A prática do enfermeiro de centro cirúrgico. São Paulo, 1995. 175p. Tese (Doutorado) - Escola de Enfermagem, Universidade de São Paulo.

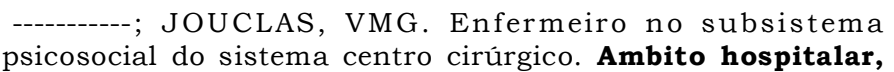
v.4, n.36, p.10-4, 1992 .

\section{BARDIN, L. Análise de conteúdo. Lisboa: Ed.70, 1977.}

BIANCHI, ERF. Estudo exploratório sobre a suspensão de cirurgia: a comunicação da suspensão e a reação relatada pelo paciente frente ao fato. São Paulo, 1983. 94p. Dissertação (Mestrado) - Escola de Enfermagem, Universidade de São Paulo.

JOUCLAS, VMG. Atuação profissional de egressos dos cursos de especialização em centro cirúrgico. São Paulo, 1993. In: CONGRESSO BRASILEIRO DE ENFERMAGEM EM CENTRO CIRÚRGICO, 1, São Paulo, 1993. Anais. São Paulo, Sociedade Brasileira de Enfermagem em Centro Círúrgico, 1994, p.196-201.

BOCK, AMB; FURTADO, O; TEIXEIRA, ML. Psicologias: uma introdução ao estudo da psicologia. São Paulo: Saraiva, 1988. 
CARAPINHEIRO, G. Saberes e poderes no hospital: uma sociologia dos serviços hospitalares. Lisboa: Afrontamento, 1993.

CAVALCANTE, JB; PAGLIUCA, LMF; ALMEIDA, PC. Cancelamento de cirurgias programadas em um hospital-escola: um estudo exploratório. Rev Latino-am enfermagem, v.8, n.4, p.59-65, 2000.

FARR, RM. Las representaciones sociales. In: MOSCOVICI, S. Psicologia social. Barcelona: Paidós, 1985. p.495-506.

FRASER, C. Attitudes, social representations and widespread beliefs. Papers Social Representations, v.3, n.1, p.13-25, 1994.

GUIMELLI, C; JACOBI, D. Pratiques nouvelles et transformatión des représentations sociales. Revue Internationale de Psycologie Sociale, v.3, n.3, p.307-34, 1990.

JODELET, D. Representations sociales: phénomènes, concept et théorie. In: MOSCOVICI, S. Psychologie sociale. Paris: Presses Universitaires de France, 1984. p.357-78.

LAPLANTINE, F. Antropologie des systèmes de représentations de la maladie. In: JODELET, D.(org.) Les Representations Socialles. Paris: Presses Universitaires de France, 1994. p.27797.

LIMA, MLP. Atitudes. In: VALA, J; MONTEIRO, MB. Psicologia social. Lisboa: Fund. Calauste / Gulbenkein, 1993. p.167-257.

MOSCOVICI, S. A representação social da psicanálise. Rio de Janeiro: Zahar, 1978.
PASSOS, ES. De anjos a mulheres: ideologias e valores na formação de enfermeiras. Salvador: EDUFBA/EGBA, 1996.

SA, CP. Representações sociais: o conceito e o estado atual da teoria. In: SPINK, MJ. O conhecimento no cotidiano. São Paulo: Brasiliense, 1993. p.19-45.

SOUZA FILHO, EA. Análise das representações sociais. In: SPINK, MJ. O conhecimento no cotidiano. São Paulo: Brasiliense, 1993. p.109-48,

SPINK, MJ. O estudo empírico das representações sociais. In: O conhecimento no cotidiano. São Paulo: Brasiliense, 1993. p.85-108.

VIEIRA, MJ. Causas e conseqüências da suspensão de cirurgias: estudo exploratório em uma cidade do Nordeste do País. Rio de Janeiro, 1982. 139p. Dissertação (Mestrado) - Escola de Enfermagem Ana Nery, Universidade Federal do Rio de Janeiro.

VIEIRA, MJ. A prática de enfermagem em centro cirúrgico e centro de material e esterilizacão nas regiões norte e nordeste. In: CONGRESSO BRASILEIRO DE ENFERMAGEM, 37, 1985, Olinda - Recife. Anais. Recife: Ass Bras Enfermagem - ABEn Pe, 1986. p.1.90-9.

YAKOTA, O. A problemática cancelamento de cirurgia conforme a expressão pelos pacientes: um estudo exploratório em um Hospital-Escola do Norte do Paraná. Ribeirão Preto, 1983. 112p. Dissertação (Mestrado) - Escola de Enfermagem de Ribeirão Preto, Universidade de São Paulo.

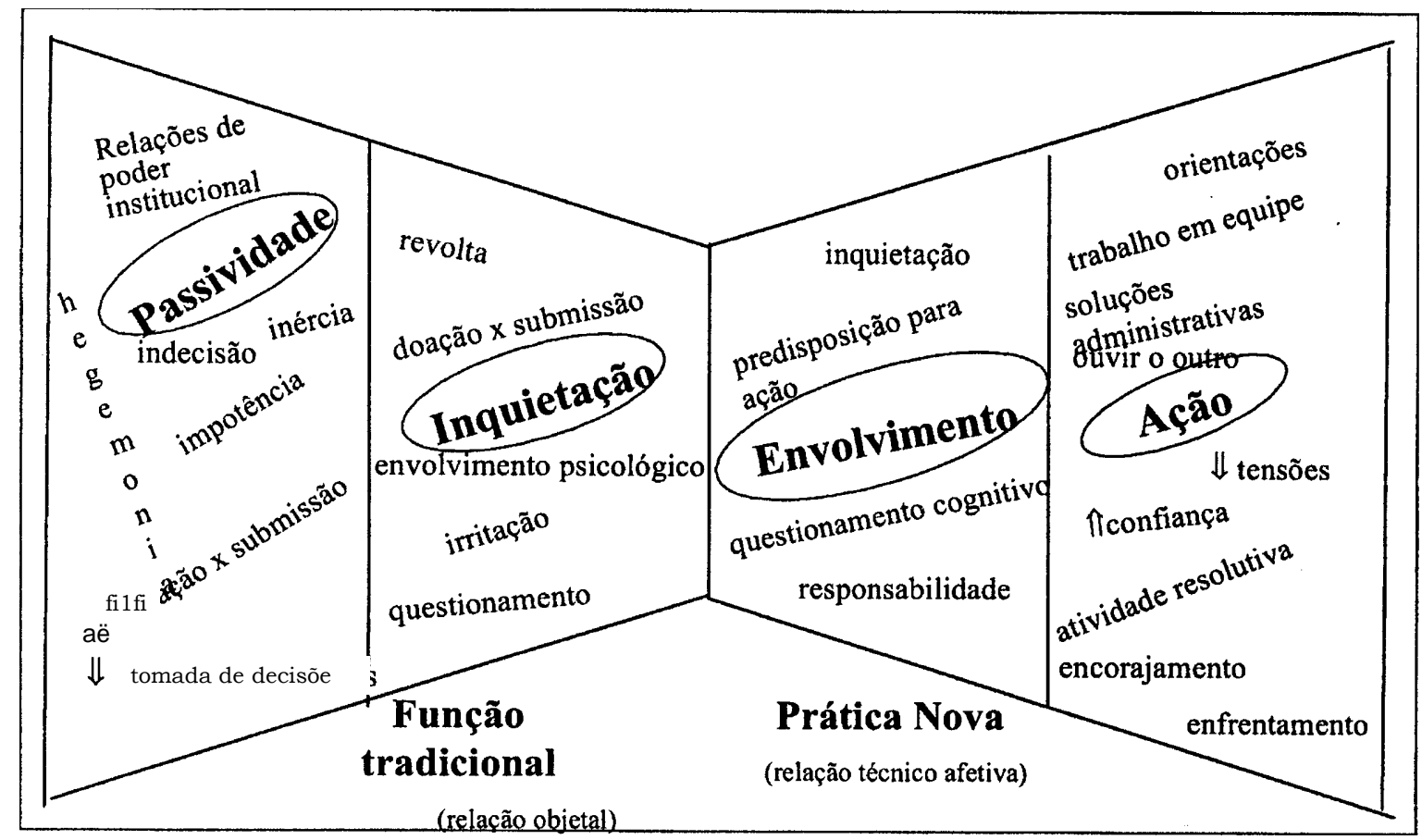

Figura - Representações Sociais sobre suspensão de cirurgias: objetivação das atitudes dos enfermeiros. 